Nanoscale Aovances

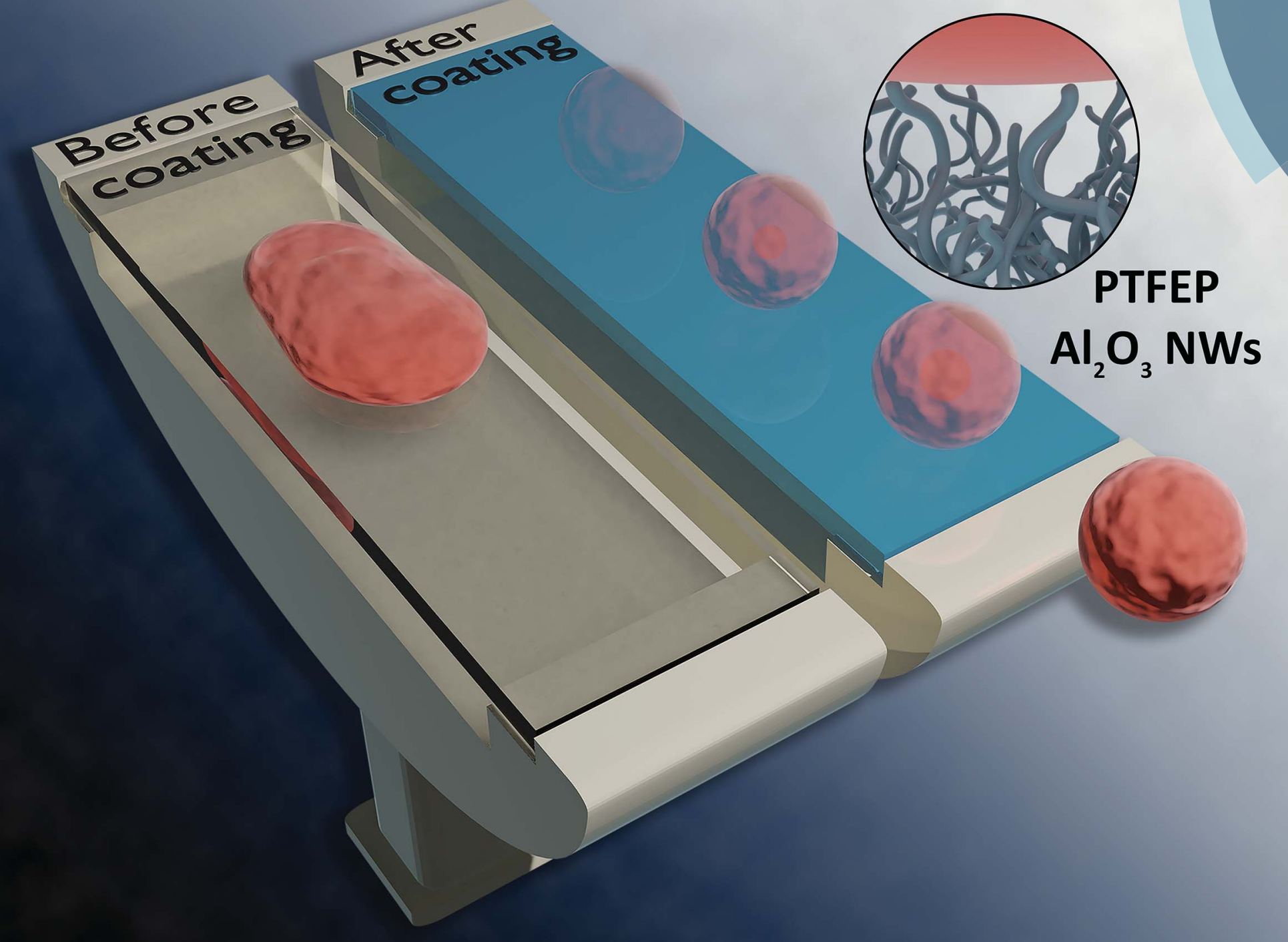

ISSN 2516-0230 
Check for updates

Cite this: Nanoscale Adv., 2019, 1, 4659

Received 12th July 2019

Accepted 15th October 2019

DOI: 10.1039/c9na00436j

rsc.li/nanoscale-advances

\section{PTFEP- $\mathrm{Al}_{2} \mathrm{O}_{3}$ hybrid nanowires reducing thrombosis and biofouling $\dagger$}

\author{
Ayman Haidar, ${ }^{a}$ Awadelkareem A. Ali, ${ }^{a}$ Salih Veziroglu, (D) ${ }^{b}$ Jacek Fiutowski, ${ }^{c}$ \\ Hermann Eichler, ${ }^{d}$ Isabelle Müller, ${ }^{d}$ Karin Kiefer, ${ }^{a}$ Franz Faupel, (D) ${ }^{b}$ Markus Bischoff, ${ }^{e}$ \\ Michael Veith, ${ }^{f}$ Oral Cenk Aktas (D) ${ }^{* a b}$ and Hashim Abdul-Khaliq ${ }^{* a}$
}

Thrombosis and bacterial infection are major problems in cardiovascular implants. Here we demonstrated that a superhydrophobic surface composed of poly(bis(2,2,2-trifluoroethoxy)phosphazene) (PTFEP) $-\mathrm{Al}_{2} \mathrm{O}_{3}$ hybrid nanowires (NWs) is effective to reduce both platelet adhesion/activation and bacterial adherence/colonization. The proposed approach allows surface modification of cardiovascular implants which have 3D complex geometries.

Superhydrophobic surfaces with water contact angles (CAs) larger than $150^{\circ}$ and slip angles (SAs) less than $10^{\circ}$ attract significant attention. ${ }^{1}$ For attaining such a superhydrophobic surface, both appropriate surface topography and low surface energy should be considered together. ${ }^{2,3}$ Besides their various technical applications in different areas including water harvesting, microfluidics, oil-water separation, and anti-icing, in recent years, superhydrophobic surfaces have been suggested to be used in cardiac implants (blood-contacting) to reduce the blood-surface interaction and bacterial adhesion., ${ }^{2,45}$

Protein binding, activation of platelets, and resultant formation of thrombi on blood-contacting cardiovascular devices remain the primary technical barriers for the success of these devices. ${ }^{6}$ In addition, bacterial infection is also a serious risk for cardiovascular implants, where $7.4 \%$ of all implanted cardiovascular devices result in bacterial infection. ${ }^{7}$ Superhydrophobic

\footnotetext{
${ }^{a}$ Department of Paediatric Cardiology, Saarland University, Building 9, 66421 Homburg, Germany.E-mail: Hashim.Abdul-Khaliq@uks.eu

${ }^{b}$ Chair for Multicomponent Materials, Institute for Materials Science, Faculty of Engineering, Christian-Albrechts-University of Kiel, Kaiserstr. 2, 24143 Kiel, Germany.E-mail: oca@tf.uni-kiel.de

${ }^{c}$ Mads Clausen Institute, NanoSYD, University of Southern Denmark, Alsion 2, 6400 Sønderborg, Denmark

${ }^{d}$ Institute of Clinical Hemostaseology and Transfusion Medicine, Saarland University, Building 1, Ringstr. 52, 66421 Homburg, Germany

${ }^{e}$ Institute of Medical Microbiology and Hygiene, Saarland University, Homburg/Saar, 66421, Germany

${ }^{f}$ INM-Leibniz Institute for New Materials, Campus D2 2, Saarbrücken, 66123, Germany

$\dagger$ Electronic supplementary information (ESI) available. See DOI: 10.1039/c9na00436j
}

surfaces are being explored for reduction of thrombus formation by minimizing material-blood interactions. In addition, such surfaces are able to inhibit bacterial adhesion.

Coating a surface composed of micro- and nanoscale topographic features with low surface energy materials (such as polytetrafluoroethylene, silicone, etc.) is a common approach to prepare a superhydrophobic surface. ${ }^{2}$ While using such structured surfaces to reduce the thrombogenicity of blood-contacting devices and implants, one should also take different matters into account. A surface topography, which reduces the effective surface area accessible to platelets, should be chosen. ${ }^{8}$ In addition, the surface morphology is also a critical issue and for instance, reducing the adhesion area exposed to individual platelets decreases the thrombogenicity. ${ }^{9}$ Moreover, highcurvature surfaces are known to induce denaturation of proteins and therefore, less adhesion of platelets. ${ }^{10}$

Failure of a cardiac device by thrombus formation can be explained by a complex series of interconnected processes which include protein adsorption, adhesion of platelets, thrombin generation, and complement activation ${ }^{11}$ as presented in Fig. S1. $\dagger$ Therefore, the reduction of protein adhesion on a surface can be an effective strategy to reduce the risk of thrombus formation. Both Wenzel and Cassie states might be effective to reduce surface area and protein adhesion sites. On the other hand, the stability of superhydrophobicity in cardiac devices and implants is a critical matter since blood-surface interaction is a hydrodynamic process rather than a static interaction. ${ }^{12}$ In the Cassie state, air pockets trapped between micro and nanoscale surface structures provide a more stable superhydrophobicity in comparison to the Wenzel state. ${ }^{13}$ Recently we have shown that the lifetime of such air pockets can be as long as several weeks and they can withstand high pressures reaching up to $150 \mathrm{~Pa}^{14} \mathrm{In}$ general, the air has a lower viscosity in comparison to water; therefore the Cassie state can cause significant slip over the surface preventing platelet adhesion. ${ }^{15}$

In addition to topography, surface chemistry also plays a major role in achieving superhydrophobicity. The surface chemistry becomes more critical in the case of using such 
superhydrophobic surfaces in blood-contacting devices and implants. In principle, both low surface energy and biocompatibility should be considered for designing blood-contacting surfaces. Polytetrafluoroethylene (PTFE) is one of the most commonly used low surface energy materials in vascular products such as angioplasty catheters, guide-wires, stent grafts, stents, and vena cava filters. ${ }^{16}$ Recently a new type of fluorinated polymer has been reported as non-thrombotic in cardiac implants. Here, a water-repellent state was achieved by the slippery liquid-infused porous surface (SLIPS) approach, in which a porous surface is covered with an immiscible perfluorocarbon liquid., ${ }^{517}$ This was accomplished by covalently binding a molecular perfluorocarbon layer, or tethered perfluorocarbon, on the material surface and then coating it with a freely mobile layer of liquid perfluorocarbons. On the other hand, reported CAs and the hysteresis are both low. Here, one of the main uncertainties with this surface is whether the presence of a high amount of fluorine in the cardiac system (since the SLIPS contains a large amount of fluorinated polymer) might lead to a long-term side effect.

Fluorinated polyphosphazenes (with an inorganic backbone of alternating phosphorus and nitrogen atoms and organic side groups) have been accepted as alternative polymers for bloodcontacting surfaces due to their inherent hydrophobicity with proven biocompatibility in preclinical and clinical settings. ${ }^{18}$ In a porcine model, PTFEP-coated stents exhibited low thrombogenicity in coronary arteries. ${ }^{\mathbf{1 9}}$ Further studies provided promising results by the reduction of not only stent thrombogenicity but also in-stent stenosis by applying PTFEP coating on stents. ${ }^{20}$ On the other hand, most of the studies on PTFEP fail to conclude whether only physicochemical properties of PTFEP coating or additional surface characteristics (topography and roughness) play a role in reducing thrombogenicity and bacterial infection. Most of these studies report the use of PTFEP as a smooth layer but applying low surface energy materials as a plain coating on smooth surfaces can enhance the non-wettability theoretically up to a CA of $120^{\circ} .^{2,21}$

In this study, the synergetic effect of the substrate topography and superior properties of PTFEP was used to develop a coating for next generation cardiovascular implants. A novel chemical vapor deposition (CVD) method (using the single-sourceprecursor concept as described elsewhere $)^{22}$ and ultrasonic infiltration technique (details of processes are given in the ESI $\dagger$ ) were used to fabricate a superhydrophobic hybrid coating, fluorinated phosphazene (PTFEP)-aluminum oxide $\left(\mathrm{Al}_{2} \mathrm{O}_{3}\right)$ nanowires (NWs, which are composed of an aluminum core and surrounding stable aluminum oxide shell), for cardiovascular implants. ${ }^{22}$ The prepared surface exhibited an extremely low solid-liquid interaction for both Ringer (used as an artificial blood model) and protein plasma fraction (PPF) solutions. $10 \mu \mathrm{L}$ drops of these solutions easily rolled-off the prepared surface at inclination angles $<1^{\circ}$ (Fig. S2 and Video S1 $\dagger$ ). In order to achieve such a repelling effect, tangled $\mathrm{Al}_{2} \mathrm{O}_{3}$ nanowires (NWs) were deposited first on a glass substrate using the single source precursor (SSP) route. $^{23}$ Next, the inorganic polymer, poly bis(2,2,2-trifluoroethoxy)phosphazene (PTFEP), was infiltrated by using an ultrasonic nozzle system (converting high frequency sound waves into mechanical energy that is transferred into a liquid, creating standing waves) into $\mathrm{Al}_{2} \mathrm{O}_{3}$ NWs (as schematically explained in Fig. 1). Basically, ultrasonic sound waves atomized the PTFEP solution into microscale droplets, and this led to a homogenous distribution and even infiltration of the PTFEP solution into the CVD driven nanoporous surface. Such a controlled and precise infiltration process kept the nanoporous morphology intact which is necessary to achieve superhydrophobicity.

Basically, the deposited layer consists of randomly grown and tangled $\mathrm{Al}_{2} \mathrm{O}_{3}$ NWs where the diameter of each NW is around 15-20 nm (Fig. 2a). The deposition temperature and time play a major role in the final surface morphology as shown previously. ${ }^{22}$ Basically, increasing the substrate temperature promotes the nucleation and the growth of $\mathrm{Al}_{2} \mathrm{O}_{3} \mathrm{NWs}$. On the other hand, since the one dimensional (1D) growth mechanism in the case of $\mathrm{Al}_{2} \mathrm{O}_{3}$ NWs is different from a typical vaporliquid-solid (VLS) approach, the initial substrate temperature also affects the diameter of the deposited $\mathrm{Al}_{2} \mathrm{O}_{3}$ NWs. At prolonged deposition periods, it was observed that the intersected $\mathrm{Al}_{2} \mathrm{O}_{3}$ NWs started coalescing and bundling together. This smoothed the over-all surface morphology, enhancing the solid-liquid contact area. Therefore, we preferred applying a moderate deposition temperature of around $500{ }^{\circ} \mathrm{C}$ (to maintain a diameter size of 10-20 nm) and an ultra-short deposition time (a few minutes) to achieve a reduced effective contact area by considering our previous process parameters. $^{24,25}$ This led to a surface coverage of $38 \%$, calculated by using a grayscale HIM image recorded at low magnification as explained elsewhere. ${ }^{26}$ For achieving a homogenous deposition within a few minutes, the precursor flow was increased by heating it to $70-75{ }^{\circ} \mathrm{C}$ and a semi-batch deposition process was used with help of an automated valve system which was opened-closed every 10 seconds regularly. Since the precursor is in the solid state, the flow rate is very sensitive to the temperature of the environment, and at room temperature, the flow

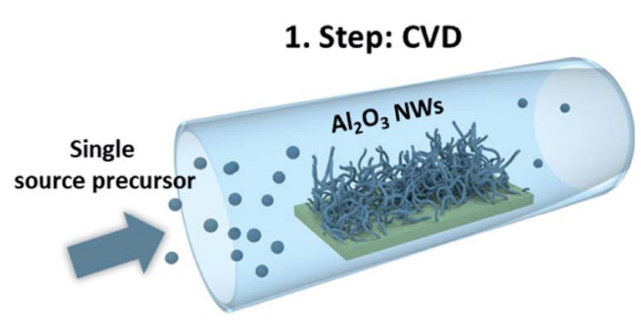

2. Step: Ultrasonic infiltration

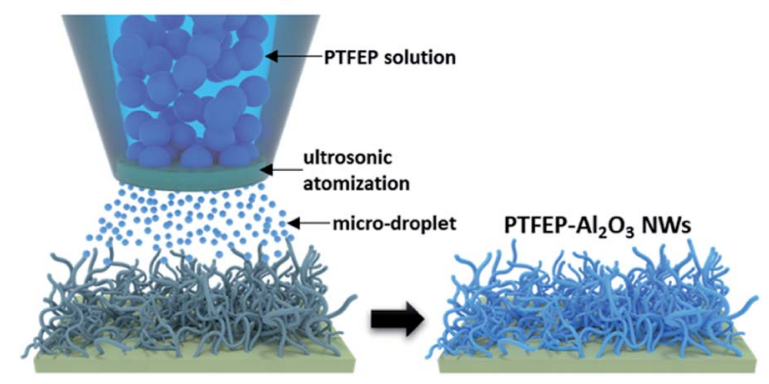

Fig. 1 Schematic description for preparation of PTFEP $-\mathrm{Al}_{2} \mathrm{O}_{3} \mathrm{NWs}$. 


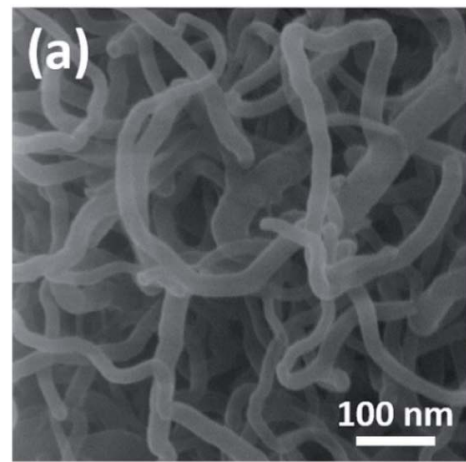

(b)
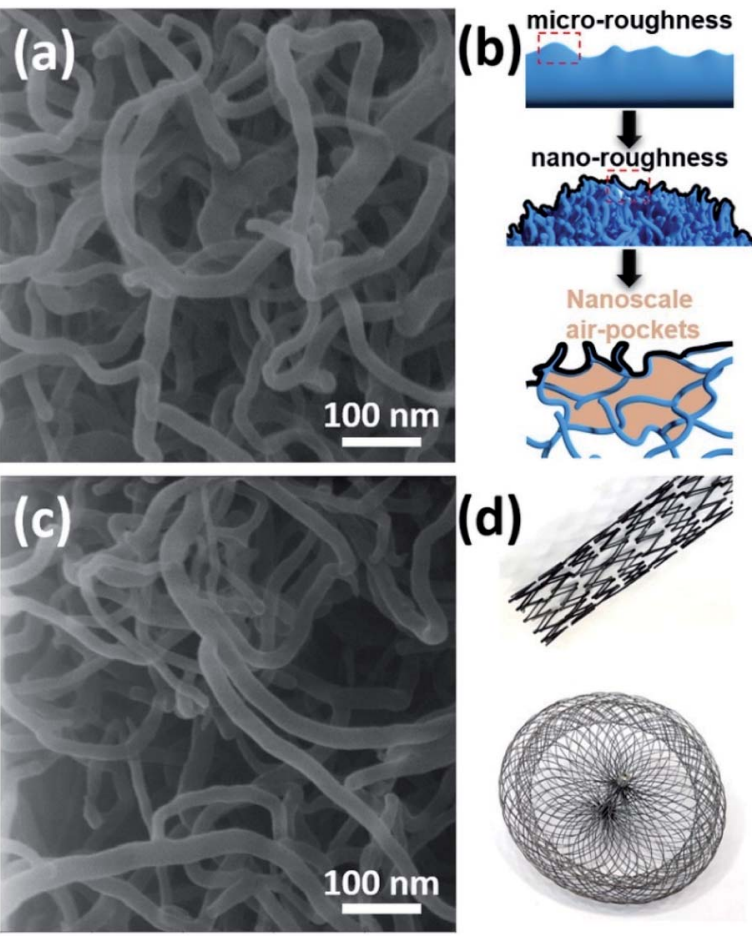

Fig. 2 (a) $\mathrm{HIM}$ image of pristine $\mathrm{Al}_{2} \mathrm{O}_{3} \mathrm{NWs}$, (b) schematic description of the surface morphology of $\mathrm{Al}_{2} \mathrm{O}_{3} \mathrm{NWs}$, (c) HIM image of PTFEP$\mathrm{Al}_{2} \mathrm{O}_{3} \mathrm{NWs}$ and (d) photos of PTFEP $-\mathrm{Al}_{2} \mathrm{O}_{3} \mathrm{NW}$ coated cardiovascular implants such as stents and occlusion devices.

rate is very limited. ${ }^{22}$ This induced a dual-scale roughness (micro- and nanoscale) and formation of nanoscale air-pockets as schematically shown in Fig. $2 \mathrm{~b}$. In the second step, the use of an ultrasonic nozzle system led to the atomization (due to ultrasonic vibrations within the nozzle) and homogenous distribution of PTFEP solution in 3D structures, which was effective to keep the so-called air-pockets intact (Fig. 2c). Basically, such nanoscale air-pockets (also known as nanoscale plastrons) with pronounced hierarchical surface roughness (bundles of $\mathrm{Al}_{2} \mathrm{O}_{3}$ NWs: microscale roughness and tangled/ intersected $\mathrm{Al}_{2} \mathrm{O}_{3}$ NWs: nanoscale roughness) form a stable air cushion within the deposited layer that leads to extremely small overall contact area between the surface and the liquid (water, Ringer solution, PPF solution and blood). ${ }^{5}$

In helium ion microscopy (HIM) images recorded at a lower magnification, one can see microscale details of the surface which exhibits local bumps and valleys due to tangled and highly intersected $\mathrm{Al}_{2} \mathrm{O}_{3}$ NWs (Fig. S3a-d $\dagger$ ). When we look closer into such bumps/valleys, a secondary roughness can be clearly seen. High magnification HIM images revealed the presence of both nanoscale roughness and nanoscale air pockets (Fig. S4a-c $\dagger$ ). The tangled geometries of $\mathrm{Al}_{2} \mathrm{O}_{3}$ NWs led to several cross-cuts and therefore the formation of nanoscale air-pockets (Fig. 2b). The combination of dual-scale roughness and nanoscale air-pockets promotes low liquid-solid interaction. Our CVD process allows using such hierarchical structures in various types of cardiovascular implants which have extremely complicated 3D geometries as shown in Fig. 2d.
CAs on PTFEP- $\mathrm{Al}_{2} \mathrm{O}_{3}$ NWs were measured by the sessile droplet method using Ringer and PPF solutions. The advancing CA for PTFEP- $\mathrm{Al}_{2} \mathrm{O}_{3}$ NWs was $168 \pm 1^{\circ}$ and the receding CA was $166 \pm 1^{\circ}$ (Fig. 3a) in the case of the Ringer solution. For the smooth PTFEP surface (coated on glass) the advancing CA was $15 \pm 1^{\circ}$ and the receding CA was $12 \pm 2^{\circ}$. It is worth mentioning that the pristine (non-modified with PTFEP) $\mathrm{Al}_{2} \mathrm{O}_{3}$ NWs were not hydrophobic at all (exhibiting a CA of $5 \pm 2^{\circ}$ ). The HIM images confirmed that the surface morphology stayed almost intact after the infiltration of PTFEP using an ultrasonic nozzle system (shown schematically in Fig. S5 $\dagger$ ). When we put a drop of PPF solution on PTFEP- $\mathrm{Al}_{2} \mathrm{O}_{3}$ NWs, the advancing CA was $163 \pm$ $1^{\circ}$ and the receding contact angle was $161 \pm 2^{\circ}$.

We examined the interaction of human blood on the prepared PTFEP- $\mathrm{Al}_{2} \mathrm{O}_{3} \mathrm{NW}$ surfaces by monitoring a drop of human blood with the help of an ultrafast video camera (complete human blood was provided by healthy donors. Prior to the sample being taken, informed consents were obtained from human participants of this study. This research has been approved by Saarland University Hospital Research Ethics Committee with an Approval ID: 90/19). It is clear from the recorded images (Fig. $3 \mathrm{~b}$ and Video $\mathrm{S} 2 \dagger$ ) that there is no visible trace of blood on the superhydrophobic surface while a large blood trail was left behind on the control surface (smooth glass). As shown from the recorded video images, the static contact angle of a $25 \mu \mathrm{L}$ blood droplet on the PTFEP- $\mathrm{Al}_{2} \mathrm{O}_{3} \mathrm{NW}$ surface was $160 \pm 3^{\circ}$ as compared to $30 \pm 2^{\circ}$ on the control (smooth glass) surface. Fig. $3 \mathrm{c}$ and Video S3† show the significant difference between blood droplets sliding on pristine (without PTFEP) $\mathrm{Al}_{2} \mathrm{O}_{3} \mathrm{NW}$ and PTFEP- $\mathrm{Al}_{2} \mathrm{O}_{3}$ NW substrates

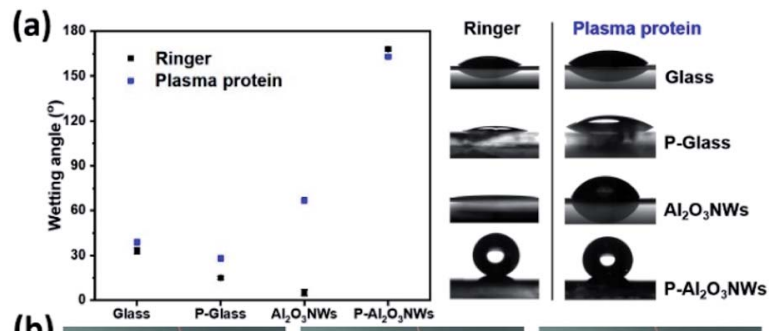

(c)
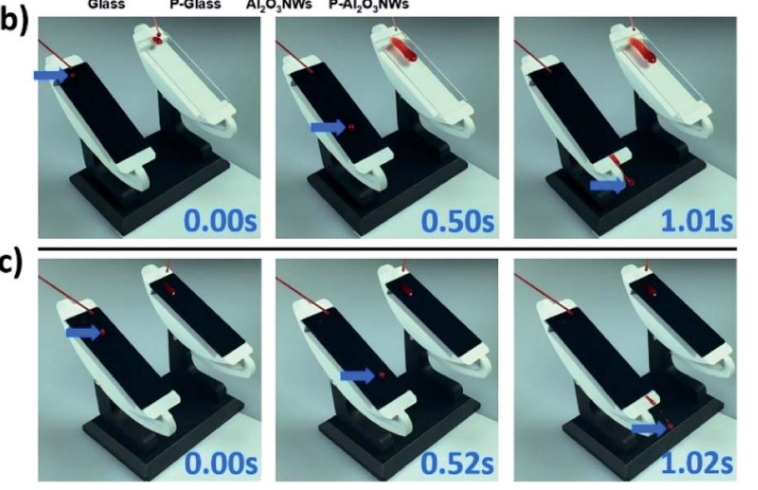

Fig. 3 (a) Contact angle analysis (insets show cross-sectional images of the corresponding droplets). Comparison of blood drop sliding on (video-captured images) (b) PTFEP- $\mathrm{Al}_{2} \mathrm{O}_{3} \mathrm{NWs}$ vs. the glass (control) substrate and (c) PTFEP $-\mathrm{Al}_{2} \mathrm{O}_{3} \mathrm{NWs}$ vs. pristine $\mathrm{Al}_{2} \mathrm{O}_{3}$ NWs. (Images were recorded using a Panasonic GH5S and extracted at a speed of 240 fps using Adobe Premiere Pro CC software.) 
tilted to $35^{\circ}$. From this, it is clear that not only the surface morphology but also the combination of nano-porous (dualscale roughness and air-pockets) nature and the low surface energy layer impacts significant blood repellency on the surface and enables blood transportation without macroscopic loss. Repeated wetting analyses showed that the prepared PTFEP$\mathrm{Al}_{2} \mathrm{O}_{3}$ NWs exhibited almost the same level of hydrophobicity even after 90 days, which may be attributed to the covalently bonded PTFEP molecules on $\mathrm{Al}_{2} \mathrm{O}_{3}{ }^{2}$

Platelet spreading and aggregation are basic markers of platelet activation and have been linked to thrombotic events. Therefore, we examined platelet response on the PTFEP- $\mathrm{Al}_{2} \mathrm{O}_{3}$ NW substrate by immediate perfusion of the surface with whole blood obtained directly from a volunteer donor (see details in the ESI $\dagger$ ). The purpose of using the whole blood is to mimic the physiological response of whole blood with all its contents including, blood cells, proteins and coagulation factors for immediate contact with artificial surfaces, which results in thrombus formation. ${ }^{27}$ Four different samples, glass (control), PTFEP-glass (PTFEP coated), $\mathrm{Al}_{2} \mathrm{O}_{3}$ NWs and PTFEP- $\mathrm{Al}_{2} \mathrm{O}_{3}$ NWs, were inserted in a specially designed holder and then the holder was coupled to a closed flow system perfused using a diagonal small neonatal pump (Medos Gmbh-Germany) with a volume capacity of $16 \mathrm{~mL}$ (Fig. S6†). All samples were inserted in the connecting piece between the two ends of a small circuit perfused using the diagonal pump. The perfusion of the coated samples was started at $25{ }^{\circ} \mathrm{C}$ for $10 \mathrm{~min}$ at a flow rate of 1500 rpm. Afterward, each surface was examined by scanning electron microscopy (SEM) to observe the platelet adhesion and aggregation behavior. A high platelet adhesion was observed on the control substrate (smooth glass) as presented in Fig. 4a. As shown in Fig. $4 \mathrm{~b}$ at a higher magnification we observed round shaped platelets and the fibrin development around the platelet body which clearly indicates the strong activation of adhered platelets. Such an aggregation of platelets on glass-like surfaces is well known as previously shown by Baker-Groberg et al. ${ }^{28}$ For comparison, the platelet response on the PTFEP modified glass substrate was monitored as shown in Fig. 4c.

At first sight (low magnification), no significant difference was observed between the bare glass and PTFEP-glass substrates in terms of platelet adhesion. On the other hand, at a higher magnification, we observed a larger amount of fibrin spread around the platelet body revealing a high level of platelet activation (Fig. 4d). This indicates that PTFEP, when deposited
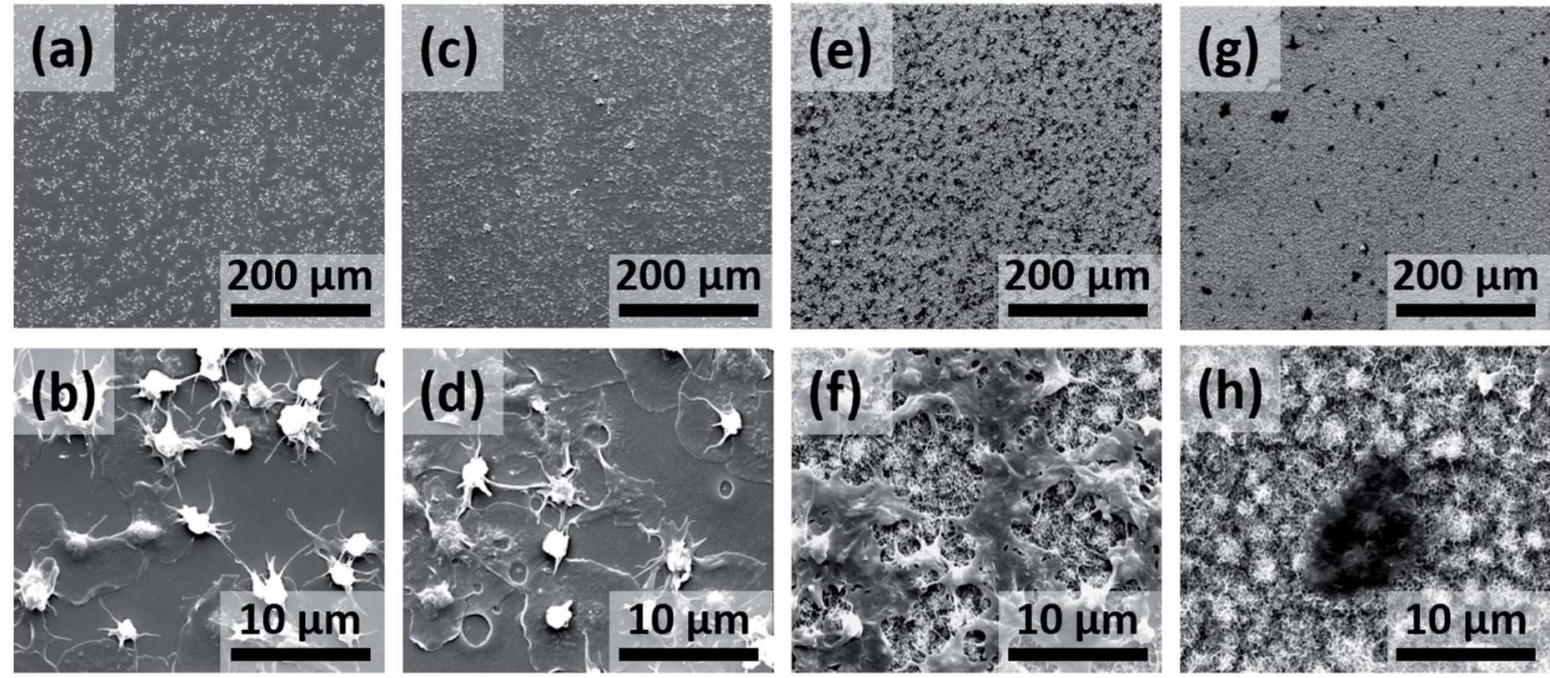

(i)

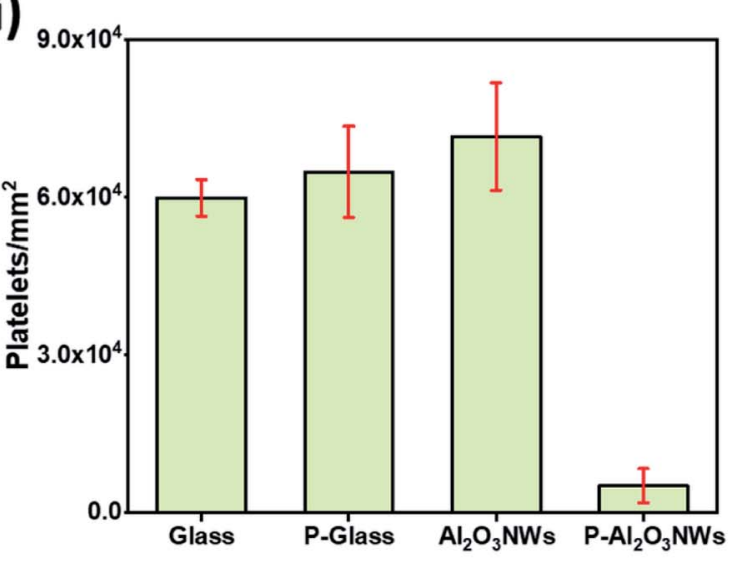

(j)

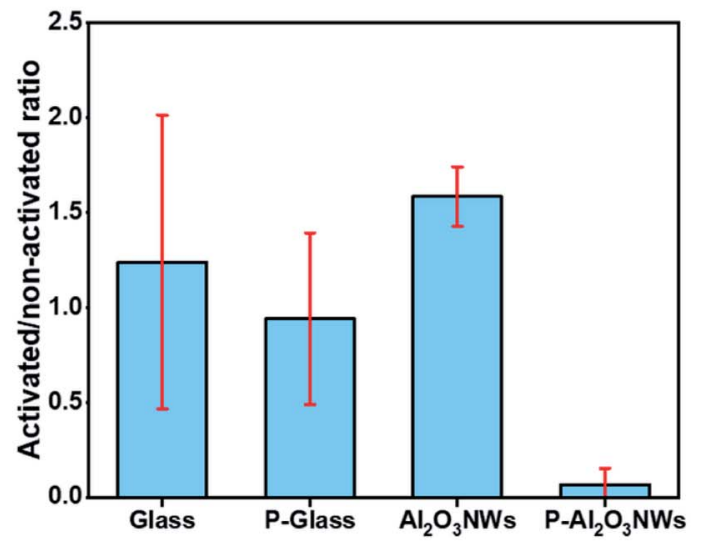

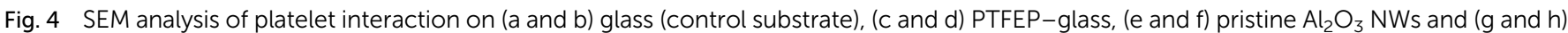

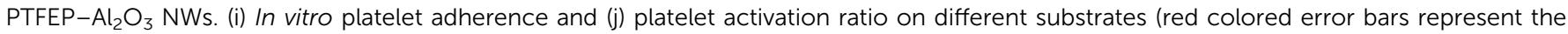
standard deviations in (i) and (j)). 
on glass, triggers thrombus formation, which is in contrast to a former study. ${ }^{19}$ After screening the effect of PTFEP on platelet adhesion and -activation we performed similar analyses on pristine and PTFEP modified $\mathrm{Al}_{2} \mathrm{O}_{3}$ NWs. It was observed that platelets were highly adhering (even higher than those observed on glass and PTFEP-glass substrates) on pristine $\mathrm{Al}_{2} \mathrm{O}_{3} \mathrm{NW}$ surfaces (Fig. 4e). $\mathrm{Al}_{2} \mathrm{O}_{3}$ NWs were previously presented as a biocompatible surface and this may explain why the platelets had high tendency to adhere on them. ${ }^{23,29}$ Additionally, Fig. 4f shows the complete activation of the platelets on pristine $\mathrm{Al}_{2} \mathrm{O}_{3}$ NWs. This phenomenon is well known on highly rough surfaces, where fibrinogen adsorption is induced leading to higher activation and strong aggregation of the platelets. ${ }^{30}$ Moreover, the stiffness and thickness of the surface matrix are known to play a major role in platelet aggregation and activation. ${ }^{31}$ This may explain the higher number of activated and aggregated platelets on the pristine $\mathrm{Al}_{2} \mathrm{O}_{3} \mathrm{NWs}$ in comparison to the glass substrate. After PTFEP modification platelet adhesion was extremely reduced, and only a few activated platelets were observed on the entire PTFEP- $\mathrm{Al}_{2} \mathrm{O}_{3}$ NWs (Fig. $4 \mathrm{~g}$ and $\mathrm{h}$ ).

The number of platelets adhering to each test surface was counted by using ImageJ software. Each sample was divided into 10 defined fields where images were taken, and platelets were counted. The experiment was repeated three times $(n=3)$. The activation and aggregation of platelets were analyzed by calculating their spread area using a one tailed $t$-test (Microsoft Excel v.16.16.8.) as presented by Radmacher et al. ${ }^{32}$ Fig. $4 \mathrm{i}$ shows an extremely low number of platelets adhering on PTFEP- $\mathrm{Al}_{2} \mathrm{O}_{3}$ NWs in comparison to other substrates $(p<0.01)$. There was a slight difference in the number of platelets attached to pristine and PTFEP modified glass $\left(5.99 \pm 0.34 \times 10^{4} \mathrm{~mm}^{-2}\right.$ and $6.48 \pm 0.87 \times 10^{4} \mathrm{~mm}^{-2}$, respectively). The number of platelets on PTFEP- $\mathrm{Al}_{2} \mathrm{O}_{3}$ NWs $\left(0.51 \pm 0.03 \times 10^{4} \mathrm{~mm}^{-2}\right)$ was significantly low compared to the number of platelets attached to pristine $\mathrm{Al}_{2} \mathrm{O}_{3} \mathrm{NWs}\left(7.15 \pm 1.02 \times 10^{4} \mathrm{~mm}^{-2}\right)$. When assessing the anti-thrombogenic potential of a surface, in addition to platelet attachment, platelet activation should also be considered. It has been shown that although the surface of a material may not support significant platelet adhesion, platelet activation may still occur. ${ }^{11}$ In general, morphological changes are one of the most commonly used criteria for assessment of platelet activation. Platelets, which remain inactivated, have a perfect lens shape and their diameter mostly stays in the 2-3 $\mu \mathrm{m}$ range. ${ }^{33-35}$ During the activation stage, platelets exhibit a more spherical shape and formation of tiny pseudopodia is observed. This is followed by development of fully spread pseudopodia structures. Based on this we tried to reveal the ratio of the activated platelets on the prepared surfaces as shown in Fig. 4j. After the exposure of platelets to test surfaces, PTEFP- $\mathrm{Al}_{2} \mathrm{O}_{3}$ NWs exhibited an extremely low platelet activation ratio, while other tested surfaces activated the adherent platelets efficiently. These findings show that PTEFP- $\mathrm{Al}_{2} \mathrm{O}_{3} \mathrm{NWs}$ do not promote platelet adhesion and activation, which are important first steps in thrombosis formation. Yet the PTEFP$\mathrm{Al}_{2} \mathrm{O}_{3}$ NWs are likely to reduce thrombus formation, still cytocompatibility tests were critical to detect whether our surface modification may exert a relevant cytotoxic effect on host tissue. (a)

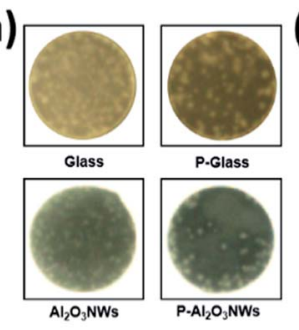

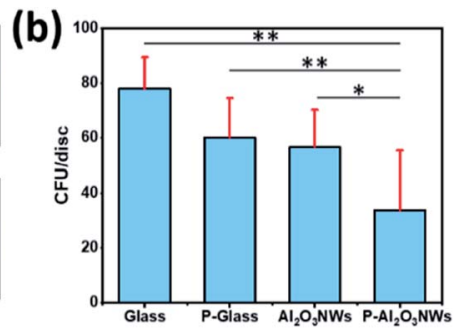

Fig. 5 In vitro bacterial colonization of Staphylococcus epidermidis on the prepared surfaces. (a) Visual analysis and (b) CFU count per disc ( $n$ $=10$ ). (*) $P<0.05$; (*) $P<0.01$ (one-way ANOVA with Bonferroni's post-hoc test).

Therefore, we studied the mediated-toxicity and the metabolic activity of human cardiomyocytes (HCM) on the prepared surfaces using LDH and WST-1 assays, respectively. Both assays did not show any significant difference between tested surfaces (Fig. S7 $\dagger$ ), indicating that the effectiveness of PTEFP- $\mathrm{Al}_{2} \mathrm{O}_{3} \mathrm{NWS}$ in the reduction of platelet adhesion and activation cannot be attributed to toxic reactions.

In addition to the risk of thrombus formation and secondary obstruction on vascular devices, bacterial adhesion colonization leading septic complications associated with implantation of intravascular devices may present a rare but serious complication after percutaneous implantation of cardiovascular devices. Superhydrophobic surfaces have been suggested as an alternative to antibiotics and biocides to reduce or even prevent bacterial colonization of implanted medical devices. ${ }^{36}$ To test the impact of our surface modifications on bacterial adhesion, we incubated these surfaces with Staphylococcus epidermidis in a microtiter plate based adhesion assay. Briefly, discs $(8 \mathrm{~mm}$ diameter) of glass, PTFEP-glass, pristine $\mathrm{Al}_{2} \mathrm{O}_{3}$ NWs, and PTFEP- $\mathrm{Al}_{2} \mathrm{O}_{3}$ NWs were fixed on the bottom of a 24 -well plate and incubated for $30 \mathrm{~min}$ in phosphate buffered saline (PBS) solution containing $1 \times 10^{4}$ colony forming units (CFU) of $S$. epidermidis strain RP62a. Discs were afterwards washed twice with PBS, placed upside-down on Luria-Bertani agar plates and incubated for $48 \mathrm{~h}$ at $37{ }^{\circ} \mathrm{C}$. Representative images of S. epidermidis colonies observed on test surfaces after $48 \mathrm{~h}$ of incubation at $37^{\circ} \mathrm{C}$ are shown in Fig. 5a.

Quantification of CFU rates formed on the test surfaces demonstrated that PTFEP- $\mathrm{Al}_{2} \mathrm{O}_{3} \mathrm{NW}$ discs displayed the lowest colonization rates (Fig. 5b). Notably, neither discs with a smooth PTFEP layer deposited on the glass substrate (P-Glass) nor discs composed of pristine $\mathrm{Al}_{2} \mathrm{O}_{3}$ NWs displayed marked reductions in colonization rates when compared to bare glass, indicating that the reduced bacterial adhesion on PTFEP- $\mathrm{Al}_{2} \mathrm{O}_{3}$ NWs required the synergetic effect of both, unique topography of $\mathrm{Al}_{2} \mathrm{O}_{3}$ NWs, and the low surface energy of the PTFEP layer.

\section{Conclusions}

In summary, synergy by combining superior topographic characteristics of $\mathrm{Al}_{2} \mathrm{O}_{3}$ NWs (without any toxicity) and low surface energy of PTFEP was proposed to reduce thrombus formation 
and bacterial adhesion for cardiovascular implants. The prepared $\mathrm{Al}_{2} \mathrm{O}_{3}$ NWs exhibited superior topographic features, which promote superhydrophobicity. The deposited $\mathrm{Al}_{2} \mathrm{O}_{3} \mathrm{NWs}$ showed a dual-scale roughness (bundles of $\mathrm{Al}_{2} \mathrm{O}_{3}$ NWs: microscale roughness and tangled/intersected $\mathrm{Al}_{2} \mathrm{O}_{3}$ NWs: nanoscale roughness). Basically, nanoscale air-pockets with pronounced hierarchical dual-scale surface roughness form a stable air cushion within the deposited layer that leads to extremely small overall contact area between the surface and blood in contact below the liquid. This reduced contact area and now-wetting nature prevent platelet adhesion and activation. The same surface also exhibits a sound anti-biofouling effect. The applicability of the proposed approach to $3 \mathrm{D}$ complex geometries makes it a strong candidate for new generation coatings for cardiovascular devices and implants in children and adults with cardiovascular diseases.

\section{Conflicts of interest}

There are no conflicts to declare.

\section{Acknowledgements}

The authors would like to thank Deutsche Herzstiftung and Herzkrankes Kind Homburg/Saar for their invaluable support.

\section{References}

1 Q. F. Xu, Y. Liu, F. J. Lin, B. Mondal and A. M. Lyons, ACS Appl. Mater. Interfaces, 2013, 5, 8915-8924.

2 A. A. Ali, A. Haidar, O. Polonskyi, F. Faupel, H. Abdul-Khaliq, M. Veith and O. C. Aktas, Nanoscale, 2017, 9, 14814-14819.

3 X.-M. Li, D. Reinhoudt and M. Crego-Calama, Chem. Soc. Rev., 2007, 36, 1350.

4 X. Zhang, F. Shi, J. Niu, Y. Jiang and Z. Wang, J. Mater. Chem., 2008, 18, 621-633.

5 V. Jokinen, E. Kankuri, S. Hoshian, S. Franssila and R. H. A. Ras, Adv. Mater., 2018, 30, 1705104.

6 E. J. Falde, S. T. Yohe, Y. L. Colson and M. W. Grinstaff, Biomaterials, 2016, 104, 87-103.

7 R. O. Darouiche, N. Engl. J. Med., 2004, 350, 1422-1429.

8 S. Movafaghi, V. Leszczak, W. Wang, J. A. Sorkin, L. P. Dasi, K. C. Popat and A. K. Kota, Adv. Healthcare Mater., 2017, 6, 1700647.

9 L. Chen, D. Han and L. Jiang, Colloids Surf., B, 2011, 85, 2-7. 10 P. Roach, D. Farrar and C. C. Perry, J. Am. Chem. Soc., 2006, 128, 3939-3945.

11 I. H. Jaffer, J. C. Fredenburgh, J. Hirsh and J. I. Weitz, J. Thromb. Haemostasis, 2015, 13, S72-S81.

12 N. Zaidi, L. V. Mclntire, D. H. Farrell and P. Thiagarajan, Transfus. Med. Rev., 1997, 11, 150-151.

13 D. Y. Kim, J. G. Lee, B. N. Joshi, S. S. Latthe, S. S. Al-Deyab and S. S. Yoon, J. Mater. Chem. A, 2015, 3, 3975-3983.

14 O. C. Aktas, S. Schröder, S. Veziroglu, M. Z. Ghori, A. Haidar, O. Polonskyi, T. Strunskus, K. Gleason and F. Faupel, $A d v$. Mater. Interfaces, 2019, 6, 1801967.
15 S. P. Jackson, W. S. Nesbitt and E. Westein, J. Thromb. Haemostasis, 2009, 7, 17-20.

16 M. T. Lam and J. Wu, Expert Rev. Cardiovasc. Ther., 2012, 10, 1039-1049.

17 D. C. Leslie, A. Waterhouse, J. B. Berthet, T. M. Valentin, A. L. Watters, A. Jain, P. Kim, B. D. Hatton, A. Nedder, K. Donovan, E. H. Super, C. Howell, C. P. Johnson, T. L. Vu, D. E. Bolgen, S. Rifai, A. R. Hansen, M. Aizenberg, M. Super, J. Aizenberg and D. E. Ingber, Nat. Biotechnol., 2014, 32, 1134-1140.

18 M. Deng, S. G. Kumbar, Y. Wan, U. S. Toti, H. R. Allcock and C. T. Laurencin, Soft Matter, 2010, 6, 3119-3132.

19 C. Henn, S. Satzl, P. Christoph, P. Kurz, B. Radeleff, U. Stampfl, S. Stampfl, I. Berger and G. M. Richter, J. Vasc. Interv. Radiol., 2008, 19, 427-437.

20 U. Stampfl, C. M. Sommer, H. Thierjung, S. Stampfl, R. Lopez-Benitez, B. Radeleff, I. Berger and G. M. Richter, Cardiovasc. Interv. Radiol., 2008, 31, 1184-1192.

21 T. Nishino, M. Meguro, K. Nakamae, M. Matsushita and Y. Ueda, Langmuir, 2002, 15, 4321-4323.

22 M. Veith, J. Lee, M. Martinez Miró, C. K. Akkan, C. Dufloux and O. C. Aktas, Chem. Soc. Rev., 2012, 41, 5117-5130.

23 K. Kiefer, J. Lee, A. Haidar, M. Martinez Miró, C. Kaan Akkan, M. Veith, O. Cenk Aktas and H. Abdul-Khaliq, Nanotechnology, 2014, 25, 495101.

24 M. Veith, E. Sow, U. Werner, C. Petersen and O. C. Aktas, Eur. J. Inorg. Chem., 2008, 2008, 5181-5184.

25 J. Lee, M. M. Miró, C. K. Akkan, A. Haidar, W. Metzger, L. K. Schwarz, V. Zaporojtchenko, K. H. Schäfer, H. AbdulKhaliq, M. Veith and C. Aktas, J. Biomed. Nanotechnol., 2013, 9, 295-298.

26 M. M. Miró, M. Veith, J. Lee, F. Soldera, F. Mücklich, R. Bennewitz and C. Aktas, J. Microsc., 2015, 258, 113-118.

27 M. Tomaiuolo, L. F. Brass and T. J. Stalker, Interventional Cardiology Clinics, 2017, 6, 1-12.

28 S. M. Baker-Groberg, F. A. Cianchetti, K. G. Phillips and O. J. T. McCarty, Cell. Mol. Bioeng., 2014, 7, 285-290.

29 W. Metzger, B. Schwab, M. M. Miro, S. Grad, A. Simpson, M. Veith, G. Wennemuth, V. Zaporojtchenko, S. Verrier, J. S. Hayes, M. Bubel, T. Pohlemann, M. Oberringer and C. Aktas, J. Biomed. Nanotechnol., 2014, 10, 831-845.

30 J. Linneweber, P. M. Dohmen, U. Kerzscher, K. Affeld, Y. Nosé and W. Konertz, Artif. Organs, 2007, 31, 345-351.

31 T.-H. Nguyen, R. Palankar, V.-C. Bui, N. Medvedev, A. Greinacher and M. Delcea, Sci. Rep., 2016, 6, 25402.

32 M. Radmacher, M. Fritz, C. M. Kacher, J. P. Cleveland and P. K. Hansma, Biophys. J., 1996, 70, 556-567.

33 W. Okrój, M. Walkowiak-Przybyło, K. Rośniak-Bąk, L. Klimek and B. Walkowiak, Acta Bioeng. Biomech., 2009, 11, 45-49.

34 M. Kuwahara, M. Sugimoto, S. Tsuji, H. Matsui, T. Mizuno, S. Miyata and A. Yoshioka, Arterioscler., Thromb., Vasc. Biol., 2002, 22, 329-334.

35 P. Yang, N. Huang, Y. Leng, J. Chen, R. K. Fu, S. C. Kwok, Y. Leng and P. Chu, Biomaterials, 2003, 24, 2821-2829.

36 X. Zhang, L. Wang and E. Levänen, RSC Adv., 2013, 3, 1200312020. 